\title{
Elektrik Tesislerinde Gerilim Kararlılığının Sağlanması için Kullanılan Yöntemler
}

\author{
Tuğçe Yeșilyurt ${ }^{1}$, Bahadır Akbal ${ }^{2}$ \\ ${ }^{1}$ Konya Teknik Üniversitesi, Mühendislik ve Doğa Bilimleri Fakültesi, Elektrik Elektronik Mühendisliği Bölümü, Konya, Türkiye (ORCID: 0000-0002-5581-8753) \\ ${ }^{2}$ Konya Teknik Üniversitesi, Mühendislik ve Doğa Bilimleri Fakültesi, Elektrik Elektronik Mühendisliği Bölümü, Konya, Türkiye (ORCID: 0000-0002- 7319-1966)
}

( $1^{\text {st }}$ International Conference on Computer, Electrical and Electronic Sciences ICCEES 2020 - 8-10 Ekim 2020)

(DOI: 10.31590 /ejosat.804207)

ATIF/REFERENCE: Yeşilyurt, T., \& Akbal, B. (2020).Elektrik Tesislerinde Gerilim Kararlılığının Sağlanması için Kullanılan Yöntemler. Avrupa Bilim ve Teknoloji Dergisi, (Özel Say1), 287-292.

Öz

Güç sistemlerinin büyümesi, hatlardaki sıkışıklığın artması nedeniyle güç sistemlerinde kararlılık kritik bir konudur. Kararlılık sorunu genellikle talep edilen reaktif gücün karşılanamamasından ve yükteki artışlardan meydana gelmektedir. Yeni hat kurulum maliyetlerinin yüksek olması nedeniyle varolan hatların maksimum kapasitede çalıştırılıyor olması da gerilim kararsızlığına sebep olmaktadır. Gerilim kararlılığında bara gerilimlerinin belirlenen güvenli sınır değerlerde kalması esastır. Gerilim değerleri bu sınırlar aralığında kalmadığı taktirde hem tüketici tarafında hem de şebeke tarafında sorunlara yol açmaktadır. Şebekeden gereğinden fazla reaktif güç çekilmesi hatlarda sıkışıklığa neden olmaktadır. Bu nedenle reaktif güç, gücün tüketileceği yere yakın bir yerden sağlanırsa hem iletim hatlarının gereksiz yüklenmesinin önüne geçilmiş olur hem de kayıplar azaltılmış olur. Ayrıca dağıtım trafoları daha fazla yükü besleyebilir. Sisteme reaktif güç desteği sağlayabilmek ve sistemi kararlı hale getirebilmek için literatürde çeşitli yöntemler kullanılmıştır. Kompanzasyon sistemleri, trafo kademe değiştiricileri, yük atma, FACTS cihazları bunlardan bazılarıdır. Bu çalışma literatürdeki çalışmaların incelemesini içermektedir.

Anahtar Kelimeler: Gerilim kararlılığı, Kompanzasyon, Reaktif güç talebi

\section{Methods Used to Ensure Voltage Stability in Power Systems}

\begin{abstract}
Stability in power systems is a critical issue due to the growth of power systems and increased congestion in lines. The stability problem usually arises from the inability to meet the demanded reactive power and increases in load. Due to the high cost of new line establisment, the fact that existing lines are operated at maximum capacity also causes voltage instability. In voltage stability, it is essential that the busbar voltages remain at the determined safe limit values. If the voltage values are not within these limits, it causes problems on both the consumer and the grid side. Excessive withdrawal of reactive power from the network causes congestion in the lines. Therefore, if reactive power is supplied from a location close to where the power will be consumed, unnecessary loading of the transmission lines is prevented and losses are reduced. In addition, distribution transformers can feed more loads. Various methods have been used in the literature in order to provide reactive power support to the system and to stabilize the system. Compensation systems, transformer tap changers, load shedding, FACTS devices are some of them. This study includes a review of the studies in the literature.
\end{abstract}

Keywords: Voltage stability, Compensation, Reactive power demand

\section{Giriş}

Elektrik enerjisine artan talep ve şebekelerdeki büyümenin sonucu olarak güç dengesinin korunması, sistemin işletim şartlarında çalıştırılabilir olması gerekmektedir. Güç sistemlerinde kararlılık; rotor açı kararlılığı, frekans kararlılı̆̆ ve gerilim kararlılığından oluşmaktadır. 
Enterkonnekte sistemlerde rotor açısı kararlılığı, senkron makinelerin bir bozulmaya maruz kaldıktan sonra senkronizmada kalabilme yeteneği olarak ifade edilmektedir. Eğer sistemde bir bozulma olmuşsa rotor ya hızlanacak ya da yavaşlayacaktır. Generatörlerden biri diğerine göre geçici bir şekilde hızlanırsa açı olarak diğerlerinin önüne geçer. Bu farktan dolayı yükün bir kısmı yavaş olandan hızlı olana doğru transfer olur. Böylece hızlar arası fark dolayısıyla açı farkı da azalır. Buradaki güç açı ilişkisi lineer olmayan bir olaydır. Bu rotor hız değişimlerinden dolayı oluşan gücü veya kinetik enerjiyi absorbe edemezse kararsızlık oluşur. (Salih Tosun, 2011)

Frekans kararlılığı büyük sistem bozulması nedeniyle üretim ve yük arasında önemli bir dengesizlik bulunduğunda güç sisteminin sabit bir frekansta kalabilme yeteneği olarak ifade edilmektedir. Frekans kararlılığında meydana gelen problemler üretim üniteleri ve yüklerdeki değişimlerden kaynaklanabileceği gibi yenilenebilir enerji kaynaklarının entegrasyonundan da kaynaklanabilir.

Gerilim kararlılığı ise bir bozucu etki sonrası sistemin normal işletim şartlarında ya da kabul edilebilir sınırlar içerisinde çalışmasını gerektirir. Sistemde gerilim kararsızlığı oluşmasındaki en büyük etken talep edilen reaktif gücün karşılanamamasıdır. Yüklerin reaktif güç talebinin artması durumunda baralarda gerilim düşmeleri meydana gelir. Bu gerilim düşmelerini dengelemek için beslemeden daha fazla akım çekilir. Bu durum ise hatların daha fazla reaktif güç tüketmesine ve yine gerilim düşmelerine ve sistemde gerilim kararsızlıklarına neden olur. Uzun süre devam eden gerilim düşmeleri sonucu gerilim çökmeleri meydana gelir. Üretim merkezlerinin tüketim merkezlerine olan uzaklığı, düşük gerilim durumlarındaki kademe değiştirme, generatör arızaları, hat kesintileri, uygun olmayan yük karakteristikleri, çeşitli kontrol ve koruma sistemleri arasındaki koordinasyon eksikliği durumları da gerilim düşmelerine neden olan etmenlerdir. Tüm bunların önüne geçebilmek, güç sistemlerinin kesintisiz, kaliteli, güvenilir ve sağlıklı çalışmasını sağlayabilmek için kararlılık çalışmaları kaçınılmaz hale gelmiştir.

Gerilim kararsızlı̆ıını önlemek ve sisteme reaktif güç desteğinin sağlanması için sistem ihtiyaçlarını karşılayacak boyutta kompanzasyon sistemleri, gerilim kontrolü gerçekleştirmek için trafo kademe değiştiricileri, generatörlerin çıkış gerilimlerini kontrol etmek için AVR'ler, aşırı yüklenmeler sonrasında koruma sistemlerinin devreye girerek hatların trip etmemesi için koruma ve kontrol sistemlerinin koordinasyonu, beklenmedik herhangi bir olay durumunda UVLS (düşük-gerilim yük atma) ile yük atma ve FACTS cihazları ile sağlanmıştır (Ahmet OVA, 2017).

(T. Yalçınöz H. Altun ve H. Karadal, 2004) güç sistemlerinde gerilim kararlılı̆ğ ve gerilim çökmelerinin MLP (Multi Layer Perceptron) tipi yapay sinir ağları kullanılarak incelemesi yapılmıştır. Sistemde generatörlerin ürettiği aktif ve reaktif güç değerleri ile generatör çıkış gerilimleri yapay sinir ağı için giriş verileri olarak alınmıştır. Tek saklı katmanlı ve iki saklı katmanlı yapay sinir ağı topolojisi ile yapılan kararlılık analizi sonuçları ve MATLAB yük akışı simülasyonundan elde edilen veriler karşılaştırılmıştır. Yapay sinir ağları ile yapılan kararlılık analizinin gerçeğe yakın sonuçlar verdiği görülmüştür. İki saklı katman topolojisindeki hata oranı daha azdir.

(Memarzadeh \& Esmaeili, 2018) Genetik Algoritma (GA) yerine Non-dominated Sorting Genetic Algorithm II (NSGA-II) kullanılmıştır. Çok Amaçı Parçacık Sürüsü Optimizasyonu (MOPSO) algoritması ile karşılaştırılmıştır. Simülasyon sonuçları, NSGAII algoritmasının diğer algoritmadan daha iyi performans verdiğini göstermektedir. Dağıtım şebekesinin koşullarını iyileştirmek için gerilim ve reaktif güç kontrolü ve dağııım şebekesinin yeniden yapılandırması kullanılmıştır. Sistemin gerçek güç kayıplarının ve bara gerilimlerindeki sapmaların minimuma indirgenmesi, gerilim kararlılık indeksinin maksimize edilmesi hedeflenmiştir. Simülasyonlarla elde edilen sonuçlar, ağın yeniden bağlanması ve volt / var kontrolünün enerji kayıplarını azaltabileceğini ve voltaj kararlılı̆̆ını artırabildiğini göstermiştir.

(Tuttokmağı \& Kaygusuz, 2019)'da yenilenebilir enerji kaynaklarına dayalı dağıtık üretim birimlerinin güç sistem kararlılığı üzerindeki etkileri incelenmiştir. Bu test sistemine çeşitli arıza senaryoları uygulanarak sistemin kararlılığı değerlendirilmiştir. İletim hattı kaybını temsil eden üç fazlı bir arıza tanımlandığında mevcut sistem kararsızlığa geçerken dağıtık üretimli sistem bir süre salınımdan sonra dengeye ulaşmıştır. Rüzgar üretim biriminin atalet sabitinde küçük artışlar meydana getirildiğinde kritik temizlenme süresinde ciddi değişiklikler olmuştur. Arıza temizlenme süresi yükseltildiğinde jeneratörlerin devre dışı kalmasına bağlı olarak kararsız hale geçmekte, bu durum güç sistemini çökertmektedir. Dağıtık üretim kaybını temsil eden bir arıza meydana getirildiğinde ise küçük güçte bile olsa enerji kaybının sistemi çökmeye kadar götürebileceği gözlenmiştir. Çalışma sonucunda dağıtık üretimin konumu, gücü, içerdiği teknoloji ve atalet sabitine göre dağıtık enerji üretiminin güç sisteminde hem pozitif hem negatif etkisi olduğu gösterilmektedir.

(Gökçek \& Ateş, 2019)'da farklı tipteki DG birimleri (Senkron generatörler, çift beslemeli asenkron generatörler, fotovoltaikler ve yakıt hücreleri) IEEE 13 baralı test sistemine entegre edilmiştir. DG birimleri bağlandıktan sonra sistemin gerilim profilinin analizi, kısa devre analizi ve sistem kayıpları analizi yapılmıştır. DG ünitelerin sisteme kontrol modunda bağlanmasıyla bara gerilimlerini aynı oranda artırdığı görülmüştür. Kısa devre katkısı analizinde ise FV'lerin sistemin kısa devre akımına katkısının oldukça az olduğu, çift beslemeli asenkron generatör ve senkron generatörün ise FV'ye göre kısa devre katkılarının daha fazla olduğu tespit edilmiş̧tir. Kayıp analizinde yapılan ilk senaryoda DG'lerin entegre edildiği barada tüketici bulunmaması olumsuz sonuçlara neden olmuştur. Ancak gerçekleştirilen ek senaryo ile aktif ve reaktif güç kayıplarının azaldığı görülmüştür. Yapılan analiz sonucunda sistemin en uzak noktasında yapılan DG entegrasyonunun en verimli sonuçlar verdiği görülmüştür.

(Yang et al., 2013)’te dağıtık rüzgar enerjisi üretiminin gerilim kararlılı̆̆ı üzerindeki etkisi incelenmiştir. Rüzgar jeneratörlerinin reaktif kompanzasyon, kapasite ve konumun dağıtım sisteminin voltaj kararlılığı üzerindeki etkisi VSI'ye (gerilim kararlılık indeksi) göre araştırmışlardır. Yaptıkları analizler sonucunda dağıtık rüzgar enerjisi üretiminin güç sisteminin gerilimini destekleyebileceği görülmüştür. 
(Baysal et al., 2007)'de elektrik güç sistemlerinde bulunan yüklerin modellenmesindeki farklılıkların gerilim kararlılık analizi üzerindeki etkisi P -V eğrileri incelenerek analiz edilmiştir. Oluşturulan test sisteminde yükler için sabit empedans-akım-güç (ZIP) modeli, bileşen tabanlı modelleme, ölçüme dayalı modelleme ve polinomsal yaklaşım kullanılmıştır. Çalışmada yük karakteristiklerinin doğru şekilde modellenmesinin güç sisteminin gerilim kararlılı̆̆ açısından önemi gözlenmiş̧ir.

Görüldüğü üzere güç sistemlerinde gerilim kararlılığını etkileyen pek çok faktör vardır. Çalışmanın devamında gerilim kararlılığı analizleri ve gerilim kararsızlığı oluşmaması için kullanılan yöntemler incelenmiştir.

\section{Materyal ve Metot}

Gerilim kararlılığı dinamik bir olay olmasına rağmen birçok uygulamada statik analizler kullanılmaktadır. Tablo 1.'de gerilim kararlılığ incelemelerinde kullanılan statik yöntemlere yer verilmiştir (Salih Tosun, 2011).

Tablo 1. Gerilim kararlılığı analizinde kullanılan statik yöntemler

\begin{tabular}{|cl|}
\hline Kullanılan Yöntem & \multicolumn{1}{c|}{ Amaç } \\
\hline Yük akışı analizi & $\begin{array}{l}\text { Yük akışı sonucunda tüm baraların gerilim genlik ve açı değerleri,iletim hatları üzerinde akan aktif ve reaktif güçleri, } \\
\text { hatlar üzerindeki kayıpları belirlemek mümkündür. }\end{array}$ \\
\hline & $\begin{array}{l}\text { Güç sistemlerinde gerilim çökme noktalarının belirlenmesinde, } \\
\text { Gerilim çökme noktasından önce baralar arasında iletilen maksimum gücün hesaplanmasında, } \\
\text { Baralarda gerilim çökmesini engellemek için gerekli olan reaktif güç kompanzasyon sistemlerinin boyutunun belirlenmesinde, } \\
\text { Generatörlerin, yüklerin ve reaktif güç kompanzasyon sistemlerinin güç sistemi üzerindeki etkilerinin değerlendirilmesinde } \\
\text { kullanılır. }\end{array}$ \\
\hline $\begin{array}{c}\text { P-V Eğrileri } \\
\text { Q-V Eğrileri }\end{array}$ & $\begin{array}{l}\text { Belirli işletme noktalarının belirlenmesi ile gerçekleştirilir. Bu işletme noktalarının oluşturduğu dizi, sürekli yük akışında } \\
\text { çzümü oluşturur. Burada çözüm, esas işletme durumundan başlar, sistemin çöküş noktası olan kritik işletme noktalarından } \\
\text { geçerek düşük gerilim bölgesine ulaşır. Yük akışı tekniğinin arkasındaki temel prensip, tahmin düzeltme basamağı üzerine } \\
\text { kurulmuştur. }\end{array}$ \\
\hline Sürekli yük akışı analizi & Gerilim kararsızlık sınırına olan yakınlık ve sistemin gerilim kararlıllğı hakkında genel bilgi vermektedir \\
\hline L İndisi & Yük artışı meydana geldiğinde sistemin denge noktalarının çatallaşması ile kararlıllı̆ın kaybolması incelenir. \\
\hline Çatallaşma analizi & $\begin{array}{l}\text { Sistemin herhangi bir yük durumu için, generatörlerin reaktif güç sınırları da göz önüne alınır, } \\
\text { ayrık yük akışı yapılarak tüm baraların gerilim ve güç değerleri belirlenir. }\end{array}$ \\
\hline Bara indirgeme analizi
\end{tabular}

Enerji santrallerinin tüketim merkezlerine olan uzaklığı üretilen enerjinin uzun iletim hatları ile taşınmasına neden olmaktadır. Bu durum ise güç sistemleri için gerilim kararsızlı̆̆ı oluşturan bir problemdir. Bu problem enerji iletim hattının maksimum yüklenebilme kapasitesiyle doğrudan ilişkilidir. Bara 1'den bara 2'ye aktarılan max güç $\mathrm{P}_{12}$ max, aktif güç $\mathrm{P}_{12}$, reaktif güç $\mathrm{Q}_{12}$, görünür güç $\mathrm{S}_{12}$ 'dir.

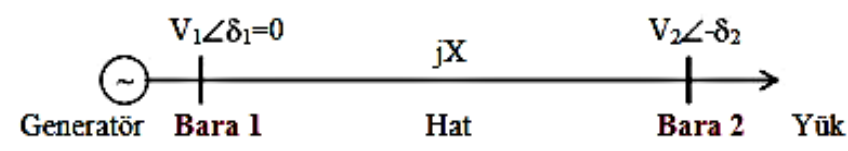

Şekil 1. 2 baralı test sistemi

$\delta$ yük açısı olmak üzere, (1-4)'te gerekli güç formülleri verilmiş̧ir.

$\mathrm{P}_{12} \max =\frac{\mathrm{V}_{1} \mathrm{~V}_{2}}{\mathrm{X}} \quad\left(\delta=90^{\circ}\right.$ iken $)$.

$P_{12}=\frac{v_{1} V_{2}}{x} \sin \delta$

$\mathrm{Q}_{12}=\frac{\mathrm{V}_{1}^{2}}{\mathrm{x}}\left(\mathrm{V}_{1}-\mathrm{V}_{2} \cos \delta\right)$

$S_{12}=V_{2} \frac{v_{1}-V_{2}}{j X}$

Yük akışı sonucunda tüm baraların gerilim genlik ve açı değerleri, iletim hatları üzerinde akan aktif ve reaktif güçler, hatlar üzerindeki kayıpları belirlemek mümkündür.

\subsection{Gerilim Kararsızlığını Önleme Yöntemleri}




\subsubsection{Geleneksel Kompanzasyon}

Reaktif güç, hatlardaki kayıpların artmasına, hattın güç iletim kapasitesinin azalmasına ve gerilim dalgalanmalarına neden olarak güç kalitesini olumsuz etkilemektedir. Bu nedenlerden dolayı güç sistemlerinde reaktif güç kompanzasyonu yapılmaktadır. Geleneksel kompanzasyon yaygın olarak sisteme paralel bağlı reaktif güç kondansatörleri ile yapılmaktadır. Bu kondansatörler yükün reaktif güç ihtiyacına göre kademeli olarak elektronik reaktif güç kontrol rölesi ve kontaktörler yardımıyla devreye alınır veya devreden çıkarılır. Kompanzasyon yapıldıktan sonra yüklerin ihtiyacı olan reaktif güç artık bu kondansatörlerden karşılanır. Kondansatörlerin seçimi ve yerleşimi de oldukça önemlidir. Kondansatörlerin reaktif güce ihtiyaç duyulan noktaya en yakın yerde konumlandırılmasının sistemin optimum şartlarda çalıştırılmasında katkısı büyüktür. Böylece iletim hatlarındaki gereksiz yüklenmelerin de önüne geçilmiş olur ve güç sisteminin kararlılığında, kontrol edilebilirliğinin, güç taşıma kapasitesinin ve verimliliğ̈inin artırılmasında önemli rol oynar.

Geleneksel kompanzasyon sistemleri gerilim genliğinin, gerilimin faz açısının ve hat empedansının kontrolüne ilişkin yavaş yük değişimlerinde ve sürekli halde yeterli olabilirler. Ancak kontaktörler rastgele anahtarlama yaptıklarından (şebeke gerilimini ve kondansatör üzerindeki gerilimi dikkate almaksızın) kondansatörlerin üzerinde aşırı geçiş akımları oluşabilmektedir. Hızlı değişen yük durumlarında da cevap süresi dakikalar sürebildiğinden reaktif güç sağlamada gecikme durumları yaşanabilmektedir. Geleneksel kompanzasyon yöntemlerinin bu gibi durumlarda yetersiz kalması ve çeşitli güç kalitesi problemleri meydana getirmesi nedeniyle FACTS cihazları üzerindeki çalışmalar artmıştır.

\subsubsection{FACTS Cihazları}

FACTS cihazları güç elektroniği tabanlı olduğundan cevap süreleri daha hızlıdır. Ani reaktif güç talebinin olduğu durumlarda tercih edilebilirdir. Mevcut hatlar üzerinde kullanılabilir olması, kontrol edilebilir olması, güç akışı kapasitesini artırması önemli avantajlarındandir.

Yapılan çalışmalar FACTS cihazlarının sistemdeki en zayıf baraya bağlanarak sistemin kararlılık sınırlarını iyileştirdiğini ve güç kaybını azalttığını göstermiştir. Bu cihazlardan en yaygın olanları:

-Statik Var Kompansatör (SVC),

-Tristör Kontrollü Seri Kondansatör (TCSC),

-Statik Kompansatör (STATCOM),

-Birleşik Güç Akışı Kontrolörü (UPFC),

-Faz Kaydırmalı Transformatör (PST)

-Statik Senkron Seri Kondansatör (SSSC)'dir.

Çalışmanın devamında çeşitli FACTS cihazlarının sistem kararlılığına olan etkisi güncel makaleler incelenerek değerlendirilmiştir.

(M. Kenan Döşoğlu, Salih Tosun, Ali Öztürk, 2013)'de yazarlar faz kaydırıcı transformatörün güç sisteminin statik kararlılığına etkilerini incelemişlerdir. Farklı faz açılarında gerilim-maksimum yüklenme parametresi ilişkisi üzerinde durulmuştur. Transformatörün faz açısı 0 'dan 10 dereceye kadar 5'er 5'er artırıldığında sistemin max yüklenme değerinin arttı̆̆ı 10-30 derece arasında ise max yüklenme parametre değerinin azaldığı görülmüştür. Özellikle 25-30 derece arasında gerilim-max yüklenme değerinin çok düştüğü gözlenmiştir.

(Salih Tosun, 2018)'de yazarlar yaptıkları çalışmada güç sistemi modelinde en yoğun yük akışının olduğu baraya faz kaydırmalı transformatör (FKT) eklemiş̧lerdir ve FKT'nin faz açısı $-45^{\prime}$ ten +45 derece aralığında değiştirilmiştir Farklı kademeler için sistemin yük akışı, sürekli yük akışı ve sistemde arıza oluşturulduktan sonraki analizler gerçekleştirilmiştir. FKT’nin faz değeri değiş̧irildiğinde hattan akan gücün değeri ve miktarı kontrol edilebilmektedir. Analizler sonucunda FKT’nin sınır değerlerinde aktif ve reaktif kayıpların arttığı, 0 derecede ise kayıpların minimum olduğu görülmüştür.

(Bozali et al., 2018)'de yapılan çalışmada, tristör kontrollü seri kompanzatör (TCSC) ve statik var kompanzatör (SVC) denetleyicilerinin güç sistemi gerilim kararlılığına ve gerilim çökmelerine olan etkilerini incelenmiştir. FACTS cihazları sayesinde güç aktarımı ve gerilim kararlılığı konusunda önemli iyileştirmeler sağlanmıştır. Şekil 2'de SVC' nin, şekil 3'te TCSC' nin devre yapıları verilmiştir.

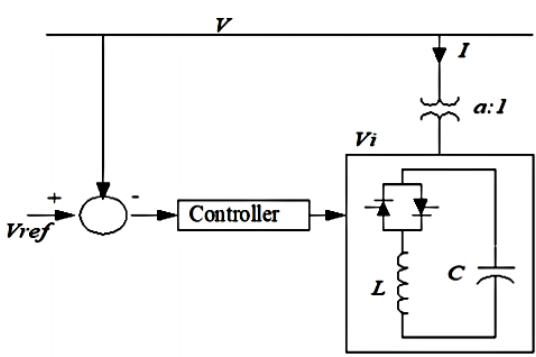

Şekil 2. SVC yapısı

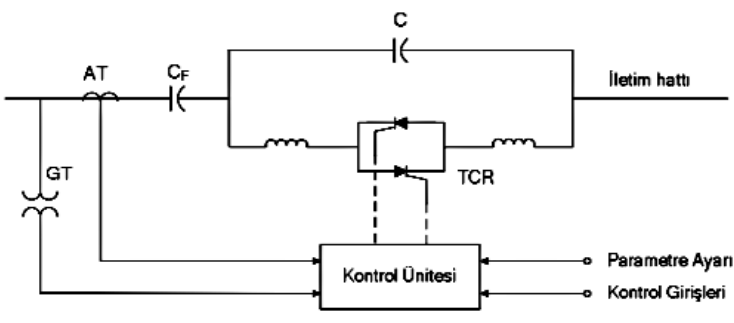

Şekil 3. TCSC yapısı

(S Tosun et al., 2011)'de yükün ani reaktif güç talebine geleneksel kompanzasyon sistemlerinin cevap süresinin yetersiz kalması sebebiyle FACTS cihazlarından olan (aynı güçteki=100MVA) SVC ve STATCOM güç sistemi modeline paralel olarak bağlanarak bir 
çalışma gerçekleştirilmiştir. SVC ve STATCOM ile elde edilen sonuçlar karşılaştırılacak olursa sisteme STATCOM bağlandığında kayıpların daha fazla azaldığı, max yüklenme parametresinin ise daha çok arttığı görülmektedir. Bu durumda gerilim çökmesi olayına karşı sistemin güvenilirliği artmıştır. Şekil 4'te STATCOM' un devre yapısı gösterilmiştir.

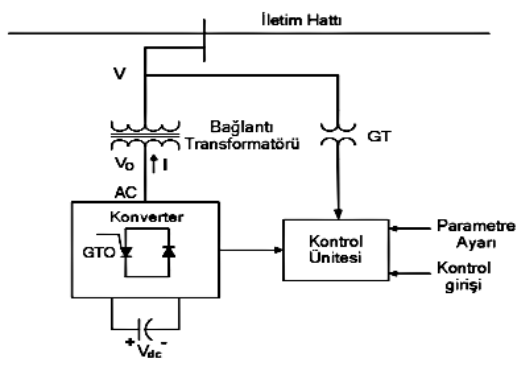

Şekil 4. STATCOM yapısı

(Ingole \& Gohokar, 2017)'deki çalışmada SSSC'nin gerilim kararlılığı ve reaktif güç kompanzasyonuna etkisi incelenmiştir. IEEE 4 baralı ve IEEE 9 baralı güç sistemleri kullanılarak MATLAB ile simule edilmiştir. Statik senkron seri kompansatör (SSSC), bir kapasitör, bir dönüş̧ürücü ve bir kuplaj transformatöründen oluşmaktadır. Çalışmada SSSC'li ve SSSC'siz modellemelere ait V, I, P, Q değerleri verilmiştir. SSSC'nin hatta seri bağlanarak hat üzerinde istenilen bir noktada voltajı kontrol edebildiği (hatta gerilim enjekte ederek) ve güç akışını sabit tuttuğu görülmüştür. Ayrıca SSSC'siz duruma göre aktif güç sönümleme süresinin de azaldığı görülmektedir. Şekil 5'te SSSC' nin devre yapısı verilmiştir.

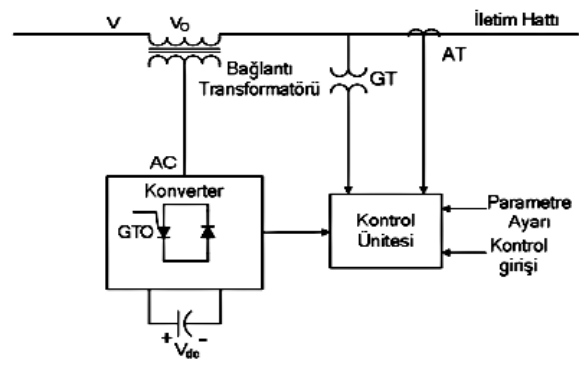

Şekil 5. SSSC yapıs1

(Muhammed Mustafa ERTAY, 2012)'de geleneksel tristör tabanlı FACTS cihazları(TCVSC, TCSC ve TCPAR) ve konverter tabanlı FACTS cihazları (STATCOM, SSSC, UPFC ve IPFC) devre yapıları, güç sistemine etkileri ve kullanım amaçları karşılaştırılmış ve incelenmiştir. FACTS Cihazlarının yatırım maliyetleri ve kısıtları ele alınmış, dünyadan ve Türkiye'den örnekler verilmiştir. Konverter tabanlı cihazlar tristör tabanlı cihazlara göre çok daha işlevsel, daha iyi performans ve uygulama esnekliği göstermektedir. STATCOM lineer çalışma aralığından dolayı büyük sistem bozunumları altında gerilim desteği sağlamada TCSVC'den üstündür.

(Masikana et al., n.d.)'de gerilim çökme noktası göstergesi ve hat kararll1ık faktörü modellenmiş ve simüle edilmiştir. Dağıtım ağında voltaj kararsızlığına yol açabilecek barayı belirlemek için çeşitli yükleme durumları dikkate alınmıştır. UPFC bağlantısı için en zayıf baralar tercih edilmiştir. Bağlantıdan sonra baraların gerilim profilinin karşılaştırmalı analizi, gerçek ve reaktif güç kayıpları ölçülmüş ve kararlılık durumu incelenmiştir. UPFC bara voltajı büyüklüğü, iki bara arasındaki faz açısı ve aynı anda veya bağımsız olarak hat reaktansını kontrol edebilmektedir. Simülasyon için 5 senaryo düzenlenmiştir. Önce sistem normal yük altında çalıştırılmıştır. Sonrasında $\% 10, \% 20, \% 30, \% 40$ yük artışında UPFC'li ve UPFC'siz olarak çalıştııılmış ve gerilim profilleri ve güç kayıpları incelenmiştir. UPFC' nin bara gerilimlerini artırarak gerilim kararsızlığından kurtardığı, sistemi kararlı hale getirdiği ve kayıpları azalttığı gözlenmiştir. Şekil 6'da UPFC' nin devre yapısı gösterilmektedir.

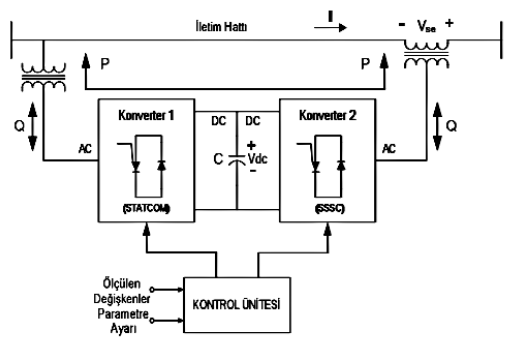

Şekil 6. UPFC yapis1 


\subsubsection{Yük Atma}

Yük atma gerilim kararlılığı sorunlarının giderilmesi için son basamaktır. Düşük gerilim değerine göre atılacak yükün konumu ve atılan yük miktarı önemlidir.

(Jianjun et al., 2018)'de geleneksel yük atma stratejilerinin eksiklerinden yola çıkılarak yeni bir strateji önerilmektedir. Önerilen yeni stratejide ana amaç, acil bir durumda yük atma stratejisini formüle ederken geri kazanım sisteminin frekans kararlılığını göz önünde bulundurarak gerilimin kararlılığını sağlamaktır. Bu stratejinin ana sürecinin iki ana adımı vardır. Öncelikle, bozulma durumuna göre sistemin girişim genliği belirlenir ve girişimin derecesi sınıflandırılır. Daha sonra, yük azaltma konumu ve ilgili baranın yük azaltımı, voltaj hassasiyetine göre belirlenir ve ardından sistemin kararlılığını yeniden sağlamak için aşırı yük hızla kaldırılır. Geleneksel strateji aktif ve reaktif güç kusurları olan alanlarda yük atmayı dikkate almadığı için, yükün rastgele kaldırılması nedeniyle her zaman hat aşırı yüklenmesine ve hatta voltaj dengesizliğine neden olma riski vardır.

(Joseph et al., 2020)'de yazarlar dağıtık enerji kaynaklarının reaktif güç kontrolüne yönelik çeşitli fiziksel ya da siber saldırılar sonucu oluşabilecek senaryolar üzerinde durmuşlardır. Böyle bir durumda dağıtım güç sisteminin dinamik davranışı ve gerilim kararlılığı incelenmiştir. 140 baralı test sisteminin farklı noktalarına 15 adet solar generation (DER) yerleştirilmiştir. Sistemin trafo merkezine bağlı OLTC Trafo ve sistemin farklı bölgelerinde SVR'ler vardır. DER ünitelerindeki reaktif güç kontrolüne yönelik çeşitli saldırı senaryoları 1 gün boyunca simüle edilmiştir. Q-V eğrisinin eğimi değiştirilmiş, Q-V eğrisinin voltaj ölü bandı değiştirilmesi, dağıtık enerji ünitelerinde akım sensöründe arıza olması, reaktif güç kontrol değerinin değiştirilmesi durumlarında SVR'lerin anahtarlama durumu, şebeke gerilim değeri, meydana gelen salınımlar gibi güç sisteminde meydana gelen değişimler incelenmiştir.

\section{Sonuç}

Elektrik tesislerinde güç talebindeki artış reaktif gücün karşılanamamasına neden olabilmektedir. Gerekli olan reaktif güç karşılanamadığı takdirde bara gerilimleri istenen seviyelerde kalmayacaktır. Bu durumda gerilim kararsızlığı kaçınılmazdır. Çeşitli yöntemler ile sisteme sağlanan reaktif güç baralardaki gerilimlerin belirli sınırlar içerisinde kalmasını sağlayarak sistemi kararsızlıktan korur. Literatürdeki çalışmalar incelendiğinde ortak amacın kayıpları azaltmak, enerji kalitesini ve verimliliğini artırmak olduğu görülmektedir. Bu çalışmada gerilim kararlılığına neden olan durumlar açıklanmış ve gerilim kararlılığının iyileştirilmesi için kullanılan yöntemler literatür incelemesi yapılarak sunulmuştur.

\section{Kaynakça}

Ahmet OVA. (2017). Güç Sistemlerinde PV-QV Ĕ̆grisi Yöntemi İle Statik Gerilim Kararlılı̆̆ı Analizi.

Baysal, M., Uzunoğlu, M., \& Kocatepe, C. (2007). Güç Sistem Gerilim Kararlılığında Yük Modellemelerinin Önemi. 12. ELEKTRIKELEKTRONIK-BILGISAYAR MÜHENDISLIĞI ULUSAL KONGRESI, 321-325.

Bozali, B., Öztürk, A., \& Tosun, S. (2018). Determination of Connection Locations of FACTS Devices to Improve Power System Stability. Nevşehir Bilim ve Teknoloji Dergisi, December 2018, 123-1. https://doi.org/10.17100/nevbiltek.443223

Gökçek, T., \& Ateş, Y. (2019). Dağıtık Güç Üretiminin Şebekeye Entegrasyonu ve Olası Etkilerinin İncelenmesi. European Journal of Science and Technology, 15, 216-228. https://doi.org/10.31590/ejosat.521350

Ingole, D. A., \& Gohokar, P. D. V. N. (2017). Voltage Stability Improvement in Multi-bus System Using Static Synchronous Series Compensator. Energy Procedia, 117, 999-1006. https://doi.org/10.1016/j.egypro.2017.05.221

Jianjun, Z., Dong, Z., Yang, G., \& Zhihong, Y. (2018). Load shedding control strategy for power system based on the system frequency and voltage stability(Apr 2018). China International Conference on Electricity Distribution, CICED, 201804230000057, 13521356. https://doi.org/10.1109/CICED.2018.8592262

Joseph, A., Smedley, K., \& Mehraeen, S. (2020). Secure Power Distribution Against Reactive Power Control Malfunction in DER Units. IEEE Transactions on Power Delivery, July 2020, 8977(c), 1-1. https://doi.org/10.1109/tpwrd.2020.3011376

M. Kenan Döşoğlu, Salih Tosun, Ali Öztürk, G. P. (2013). Faz Kaydırıcı Transformatörlerin Statik Gerilim Kararlılı̆̆ Etkilerinin İncelenmesi. Journal of Advanced Technology Sciences, 2(3), 43-52.

Masikana, S. B., Sharma, G., Akindeji, K., \& David, I. E. (n.d.). Voltage Stability Enhancement Studies for Distribution Network with Installation of FACTS.

Memarzadeh, G., \& Esmaeili, S. (2018). Voltage and reactive power control in distribution network considering optimal network configuration and voltage security constraints. Scientia Iranica, O(0), 0-0. https://doi.org/10.24200/sci.2018.20565

Muhammed Mustafa ERTAY, Z. A. (2012). Güç sistemleriınde facts uygulamalart. 4(2), 40-58.

Salih Tosun, A. Ö. (2018). Faz Kaydırıcı Transformatörlerin Dinamik Gerilim Kararlılı̆̆ına Etkileri. 469-480.

T. Yalçınöz H. Altun ve H. Karadal. (2004). Farklı Topolojiye Sahip MLP Yapay Sinir Ağları ile Enerji Sistemlerinde Gerilim Kararlılı̆̆ı Analizi. The 13thTurkish Symposium on Artificial Intelligence and Artificial Neural Networks, Pp. 547-554, June 10-11 2004, İmir, Turkey.

Tosun, S, Öztürk, A., Yalçın, M., Döşoğlu, K., \& Güvenç, U. (2011). Güç Sisteminde SVC ve STATCOM Denetleyici Etkilerinin İncelenmesi. International Advanced Technologies Symposium (IATS'11), 16-18 May 2011, Elazlğ, Turkey Güç, 287-292. http://web.firat.edu.tr/iats/cd/subjects/Electrical\%26Electronics/EAE-60.pdf

Tosun, Salih. (2011). Güç Sistemlerinde Gerilim Kararlılı̆̆ının Sezgisel Yöntemlerle Incelenmesi.

Tuttokmağ1, Ö., \& Kaygusuz, A. (2019). Transient Stability Analysis of Power Systems with Distributed Generation. 2019 International Conference on Artificial Intelligence and Data Processing Symposium, IDAP 2019. https://doi.org/10.1109/IDAP.2019.8875935

Yang, J., Li, G., Wu, D., \& Suo, Z. (2013). The impact of distributed wind power generation on voltage stability in distribution systems. Asia-Pacific Power and Energy Engineering Conference, APPEEC. https://doi.org/10.1109/APPEEC.2013.6837205 